\title{
Research on Evaluation System of Vibration Induced by Shield Construction
}

\author{
Tao Lianjin ${ }^{1}$, Guo Fei ${ }^{1}$, Wang Guofeng ${ }^{2}$, Huang Jun ${ }^{3}$, An Junhai ${ }^{1}$, Liu Chunxiao ${ }^{1}$, Bian Jin ${ }^{1}$ \\ ${ }^{1}$ Key Laboratory of Urban Security and Disaster Engineering of Ministry of Education, Beijing University of Technology, Beijing, China \\ ${ }^{2}$ Beijing Railway Construction and Management Co.Ltd., Beijing, China \\ ${ }^{3}$ CCTEB Civil Defense and Underground Space Institute, Wuhan, China
}

\section{Email address:}

ljtao@bjut.edu.cn (Tao Lianjin), guofei2007@163.com (Guo Fei), 728989294@qq.com (An Junhai), 1070672142@qq.com (Liu Chunxiao), bianjin66@163.com (Bian Jin),18810610118@163.com (Wang Guofeng),37195274@qq.com (Huang Jun)

\section{To cite this article:}

Tao Lianjin, Guo Fei, Wang Guofeng, Huang Jun, An Junhai, Liu Chunxiao, Bian Jin. Research on Evaluation System of Vibration Induced by Shield Construction. American Journal of Civil Engineering. Vol. 4, No. 3, 2016, pp. 92-97. doi: 10.11648/j.ajce.20160403.15

Received: March 7, 2016; Accepted: April 14, 2016; Published: May 24, 2016

\begin{abstract}
The research of vibration induced by rail transit should not only consider operation stages, but also extend to the construction phase. Based on the calculation results of site test, the evaluation index system was proposed which is suitable for vibration induced by shield construction. The evaluation indexes were built for the first time and the weight coefficient method was used to determine the weight of each evaluation index. According to actual application of evaluation project, the vibration level was described by Fuzzy language, then the evaluation index system of vibration induced by shield construction was established, which is verified by a project example. The research result shows that: the vibration induced by shield construction can be directly present by the evaluation indexes assessment system which was based on site test, so the leading factors can be effectively traced. Afterwards, a reasonable level of vibration and corresponding risk control measures can be gotten, then the satisfactory assessment result was obtained at last. The evaluation index system of vibration induced by shield construction provides some reference datum for the vibration sensitive area by shield construction.
\end{abstract}

Keywords: Subway, Environmental Vibration, Evaluation Index, Shield Construction

\section{Introduction}

In recent years, shield construction has been widely used in China, owing to its safety, construction speed, little disturbance to the surrounding environment and many other advantages. The environmental shield construction induced vibration problems in Beijing western typical sand and gravel stratum resulted in disturbing event, people repeatedly complained petitions and resulted in work stoppage for several months [1]. Vibration rail should not only consider the operational phase, but should extend to the construction phase.

For the vibration induced by subway construction, only have few studies, which focus on the vibration problem in the rock layer caused by TBM tunneling. On the basis of field measurement and numerical modeling, scholars (Tao Linjin [2], Wang Xin [3]) has paid very close attention to environmental vibration problem caused by shield tunneling to the adjacency of railway lines to some sensitive residential areas such as hospitals, research centers, laboratories, or buildings with highly sensitive instruments, relying on specific projects.

In order to study the influence of ground vibration induced by shield tunneling in gravel formation to high precision factory, test was carried out in Taiwan [4]. The scholars put forward the knife dish speed reduction and illustrate the Type of article (Spoke Type) panel, increase rate of the knife dish openings (about 60\%, average 45\%) measures to weaken vibration.

Rapid metro light rail transit (LRRT) in Buffalo, New York City in the United States, TBM tunneling induced vibration in hard rock. Scholars [5] has carried on the detailed research, and put forward the formula vibration attenuation rate.

In this regard, various aspects of the problems have been investigated in the following three major fields.

Vibration generation: Vibration of the railway track system under a moving load; 
Vibration transmission: Transmission of vibrations along the rail to the surrounding environment;

Vibration reception: Response of structures neighboring the tracks to the vibrations.

Existing research shows: people disturbed during construction lots in severe vibration environment during the operation of the inevitable outstanding. Based on current research findings and ideas evoked shield construction civil engineering risk assessment, proposed a comprehensive on-site evaluation of measurement results and risk indicators assessment methods, in order to be able to shield construction induced vibration is given to environmentally sensitive areas quantitative reasonable evaluation, and the corresponding damping action, and to provide reference and guidance for the study of train operations generated vibration.

\section{Overall Evaluation System of Vibration Induced by Shield Construction}

For shield construction induced environmental vibration assessment, we recommended target system, the law proposed by Richards [6] in 1999 and gradually attracted people's attention.

The most important factor in the evaluation of risk assessment system is to assess the merits of the selection of indicators suggest prominent characteristics of the object, and the reaction of both its nature and general, the assessment should be a comprehensive and representative indicators, this paper using two target system, the choice of degree-level indicators most direct response structural safety factors, two indicators to quantify and subdivision level on the basis of the indicators in order to divide the risk impacts [7].

Overall evaluation system vibration-induced environmental shield construction paper selected and the corresponding values of the standard shown in Table 1.

According to the mechanism of vibration transmission, primary index consists of three main parts: (1) vibration sources; (2) transmission-vibration with the surrounding rock mass propagation; (3) by the vibration body - Sensitivity Buildings.

Shield of penetration [8]: shield advance velocity $v$ and the ratio of the cutter head speed $\mathrm{n}$, expressed with $P_{\text {rev }}$, its physical meaning is the knife dish after every rotation knives of excavation depth, namely the $P_{\text {rev }}=v / n$.

Depth: according to the code for metro design (GB50157-2003), shield method construction of tunnel overburden soil thickness not less than outside the tunnel contour diameter, and the Beijing metro tunnel at the top of the overburden soil thickness is generally not more than $20 \mathrm{~m}$.

Soil dynamic weighting modulus of elasticity, excavation face involves the formation of dynamic modulus of elasticity according to the weighted average of the total area, reflects the degree of hardness and dense soil excavation surface

Horizontal distance: considered rail transit environment vibration attenuation with distance, in a certain distance attenuation will be slow, does not decay, and even distance increases slightly magnified "local amplification effect", score $10 \sim 30 \mathrm{~m}$ within the scope of the strengthen [9].

Vibration body: according to the design of buildings, residential buildings and similar protection value of ancient buildings or on vibration sense except for hospitals and research institutes.

Table 1. The evaluation index system of vibration induced by shield construction.

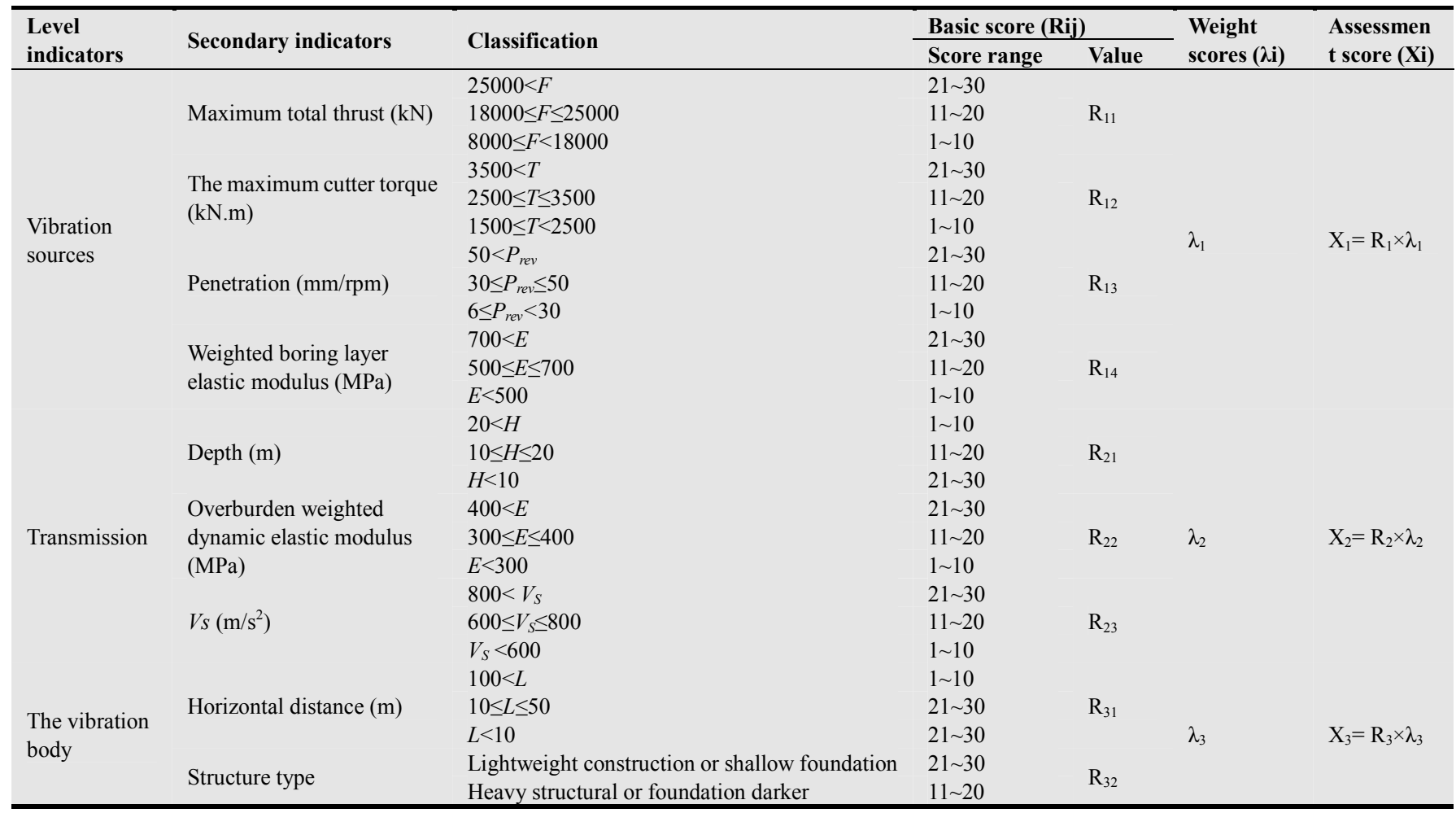




\section{Vibration Classification}

For a specific project, the proportion of the environmental impact assessment index different vibrations, recommended weight coefficient method to distinguish their importance, which is calculated as follows:

$$
\lambda=\frac{2 \mathrm{n}-2 \mathrm{~m}+1}{n^{2}}
$$

Where: $\lambda$ - weighting coefficient: $n$ - evaluation index number of items; $m$ - number in order of importance, $m \leq n$.

Thus, the shield construction induced environmental vibration assessment value $\mathrm{X}$ calculated to determine:

$$
\begin{aligned}
& X=\sum R_{j} \lambda_{j} \\
& R_{j}=\sum R_{i j}
\end{aligned}
$$

Where: $i=1,2,3,4 ; j=1,2, \cdots \cdots, n$.

$n$ is the number of key indicators corresponding to the $\mathrm{i}$ level indicators included.

After the calculated $X$, Chart 2 to determine the level of environmental vibration induced by shield construction.

Table 2. The classification standard of vibration induced by shield construction.

\begin{tabular}{ll}
\hline Risk level & Assessment score \\
\hline Level IV (high grade) & $\mathrm{X}>50$ \\
Level III (height) & $40<\mathrm{X} \leq 60$ \\
Level II (moderate) & $20<\mathrm{X} \leq 40$ \\
Level I (low) & $0<\mathrm{X} \leq 20$ \\
\hline
\end{tabular}

Note: The grading standards in accordance with the central limit theorem.

\section{Control of Vibration Induced by Shield Construction}

For shield construction induced vibration studies in order to control the effects of vibration on the surrounding environment.

Measures ambient vibration damping and noise reduction is generally based on their propagation mechanisms: reduce vibration from the vibration source; the barrier vibration propagation path; enhance vibration body vibration capability by itself.

Based on the results of the assessment of environmental vibration, made with the corresponding vibration and noise

\begin{tabular}{|c|c|c|}
\hline Risk level & $\begin{array}{l}\text { Acceptance } \\
\text { criteria }\end{array}$ & Control Measures \\
\hline Level I (low) & Negligible & No action required \\
\hline Level II (moderate) & Acceptable & $\begin{array}{l}\text { By changing the parameters of } \\
\text { shield to active vibration reduction }\end{array}$ \\
\hline Level III (height) & Do not expect & $\begin{array}{l}\text { We must take appropriate damping } \\
\text { measures and organizational } \\
\text { experts }\end{array}$ \\
\hline Level IV(high grade) & Unacceptable & $\begin{array}{l}\text { Change the line location or take } \\
\text { special measures to reduce } \\
\text { vibration }\end{array}$ \\
\hline
\end{tabular}
reduction countermeasures. As shown in Table 3.
Table 3. The countermeasure of vibration induced by shield construction.

\section{Example}

\subsection{Project Background}

The test location was selected in some right line tunnel of Beijing subway, which tunnel structure Outer diameter is 6.0 $\mathrm{m}$ and lining thickness is $0.3 \mathrm{~m}$. The depth of shield was about $12 \sim 15.5 \mathrm{~m}$, covering three main layers, respectively miscellaneous fill soil, silty clay and floated pebble stone. Shield crossing section for gravel layer (4), the circular, continuous gradation, roundness medium, the particle size commonly $2 \sim 10 \mathrm{~cm}$, maximum particle size of about $19 \mathrm{~cm}$, coarse sand filling in 20\% 25\%, local with boulders, average particle size of $21 \sim 26 \mathrm{~cm}$, the biggest size is about $56 \sim 70 \mathrm{~cm}$, boulders content is about $20 \% \sim 6 \%$. Layer parameters of court areas as shown table 4. This section used the earth pressure balance shield machine construction, panel cutter head, cutter opening rate was $38 \%$. Shield cutter disc configuration as shown in figure 1.

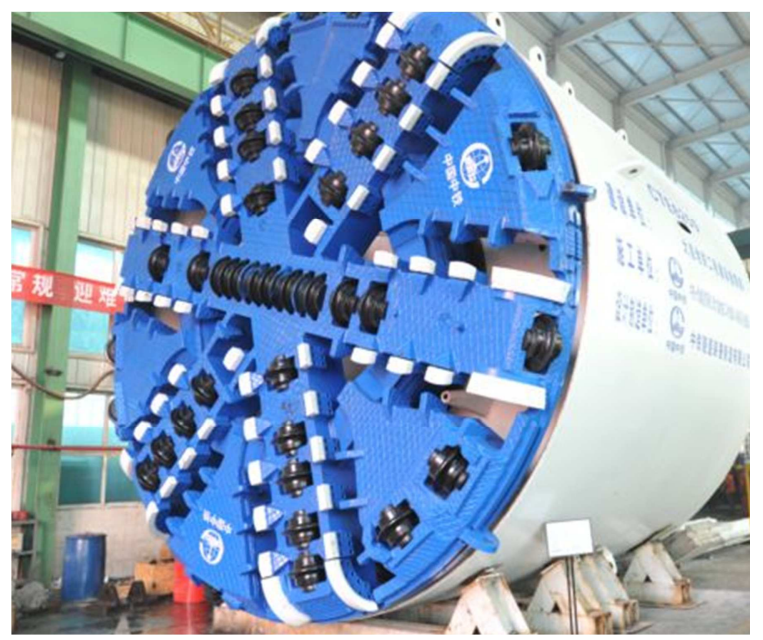

Fig. 1. Shield machine.

Table 4. Layer parameters of court areas.

\begin{tabular}{lllll}
\hline Formation Name & Thickness $(\mathbf{m})$ & P $\left(\mathbf{k g} / \mathbf{m}^{\mathbf{3}}\right)$ & Vs $(\mathbf{m} / \mathbf{s})$ & Dynamic elastic modulus $(\mathbf{M P a})$ \\
\hline Plain fill & 4 & 1600 & 168 & 143 \\
Silty sand & 3 & 1950 & 173 & 266 \\
Pebble, Round ravel & 7 & 2100 & 313 & 582 \\
pebble & - & 2300 & 345 & 674 \\
\hline
\end{tabular}


Based on the vibration transmission main controlling factor is the depth of research and formation of consensus, level indicators of the present evaluation system to assess the extent of the order of importance: Pathways $>$ by vibration body $>$ vibration source, based on the weight coefficient calculation formula to obtain the corresponding coefficients were $5 / 9,3 / 9$, $1 / 9$.

Table 5. The evaluation index system of vibration induced by shield construction.

\begin{tabular}{|c|c|c|c|c|c|}
\hline Level indicators & Secondary indicators & Classification & Value & Weight scores $(\lambda \mathbf{i})$ & Assessment score (Xi) \\
\hline \multirow{4}{*}{$\begin{array}{l}\text { Vibration } \\
\text { sources }\end{array}$} & Maximum total thrust & $F=34000 \mathrm{kN}$ & $\mathrm{R}_{11}=30$ & & \multirow{4}{*}{$X_{1}=43$} \\
\hline & The maximum cutter torque & $T=5000 \mathrm{kN} \cdot \mathrm{m}$ & $\mathrm{R}_{12}=30$ & $\lambda_{1}=5$ & \\
\hline & Penetration & $P_{\text {rev }}=42 \mathrm{~mm} / \mathrm{rpm}$ & $\mathrm{R}_{13}=17$ & 9 & \\
\hline & Weighted boring layer elastic modulus & $E=674 \mathrm{MPa}$ & $\mathrm{R}_{14}=12$ & & \\
\hline \multirow{3}{*}{ Transmission } & Depth & $H=14 \mathrm{~m}$ & $\mathrm{R}_{21}=14$ & \multirow{3}{*}{$\lambda_{2}=\frac{3}{9}$} & \multirow{3}{*}{$\mathrm{X}_{2}=12$} \\
\hline & Overburden weighted dynamic elastic modulus & $E=389 \mathrm{MPa}$ & $\mathrm{R}_{22}=18$ & & \\
\hline & Vs & $V_{S}=242 \mathrm{~m} / \mathrm{s}^{2}$ & $\mathrm{R}_{23}=3$ & & \\
\hline \multirow{2}{*}{ Vibration body } & Horizontal distance & $L=1000 \mathrm{~m}$ & $\mathrm{R}_{31}=10$ & \multirow{2}{*}{$\lambda_{3}=\frac{1}{9}$} & \multirow{2}{*}{$\mathrm{X}_{3}=3$} \\
\hline & Structure type & Frame structure & $\mathrm{R}_{32}=15$ & & \\
\hline
\end{tabular}

Therefore, in accordance with the evaluation system of this paper, the environmentally sensitive region overall assessment score $X=43+12+3=58$, belonging to grade III (height). So it may surpass the daytime limit requirements of cultural and educational areas $70 \mathrm{~dB}$ in Urban regional environmental vibration standards, and we must take specific damping measures, organizational experts, then conducted shield construction.

\subsection{Field Test}

The instruments used in the test were WS-5921 Data Acquisition \& Signal Processing System, and 941B ultra-low frequency acceleration sensors and amplifier. All instruments and sensors were calibrated before the field test. Sampling frequency of this test was $200 \mathrm{~Hz}$. Urban regional environmental vibration testing method (GB10071-88) [10] was strictly executed in the process of testing.

Vibration measurements have been performed on the bedroom, hall and kitchen, both at the basement, the second floor and eighth floor of a 9 floors box shear structure residential building.

\subsection{Test Results}

\subsubsection{A Third Octave Spectrum Analysis}

A third octave spectrum, a frequency domain analysis method, has the characteristics of spectral line less bandwidth, which is often used in acoustics, in the human body vibration, mechanical vibration test and analysis. According to the regulations of the current standard, the center frequency of $1 \mathrm{~Hz}, 1.25 \mathrm{~Hz}, 1.6 \mathrm{~Hz}, 2.0 \mathrm{~Hz}, 2.5 \mathrm{~Hz}, 3.15 \mathrm{~Hz}, 4 \mathrm{~Hz}, 5 \mathrm{~Hz}, 6.3 \mathrm{~Hz}$,
$8 \mathrm{~Hz}, 10 \mathrm{~Hz}, \ldots$. A third octave spectrum, lower limit of the relationship between the frequency and the center frequency is as follows.

$$
\frac{f_{u}}{f_{l}}=2^{1 / 3}, \frac{f_{c}}{f_{l}}=2^{1 / 6}, \frac{f_{u}}{f_{c}}=2^{1 / 6}
$$

A third octave spectrum bandwidth is $\Delta f=f_{u}-f_{l}$ : which is $f_{l}$ lower limit frequency, $f_{c}$ as the center frequency, $f_{u}$ for on-line frequency. First FFT transform was carried out on the test data, calculate the amplitude spectrum, then use amplitude spectrum data calculated the average of the data in each of the center frequency bandwidth, and a third octave spectrum value is obtained.

\subsubsection{Environmental Assessment Vibrations in GB}

According to Standard of vibration in urban area environment (GB10070-88) [11] regulation, the vertical vibration to $\mathrm{Z}$ level calculated in accordance with the type:

$$
V L_{z}=20 \times \lg \left(a_{r m s}^{\prime} / a_{0}\right)
$$

Type, $a_{0}$ benchmark for acceleration, average value of $10^{-6} \mathrm{~m} / \mathrm{s}^{2} ; a_{r m s}^{\prime}$ for vibration acceleration RMS, generally considered $a_{r m s}^{\prime}=\sqrt{\sum a_{f r m s}^{2} \times 10^{0.1 c_{f}}}, \quad c_{f}$ to vibration acceleration level feeling revised, $a_{f r m s}$ as the center frequency acceleration RMS. 
Table 6. 1/3 octave spectrum calculation of measuring point (dB).

\begin{tabular}{|c|c|c|c|c|c|c|c|}
\hline \multirow{2}{*}{ 1/3oct/(Hz) } & \multirow{2}{*}{ Limit } & \multicolumn{2}{|c|}{ Basement } & \multicolumn{2}{|c|}{ Second floor } & \multicolumn{2}{|c|}{ Eighth floor } \\
\hline & & Vertical & Horizontal & Vertical & Horizontal & Vertical & Horizontal \\
\hline 1 & 76 & 43.9 & 43.7 & 48.3 & 49.8 & 43.4 & 43.7 \\
\hline 1.25 & 75 & 45.0 & 42.4 & 48.9 & 49.8 & 46.3 & 46.5 \\
\hline 1.6 & 74 & 46.8 & 45.9 & 50.3 & 52.6 & 47.4 & 47.8 \\
\hline 2 & 73 & 45.6 & 43.0 & 45.8 & 49.0 & 51.3 & 50.8 \\
\hline 2.5 & 72 & 48.9 & 48.0 & 48.5 & 51.1 & 44.9 & 45.2 \\
\hline 3.15 & 71 & 47.7 & 48.4 & 48.2 & 49.3 & 46.1 & 46.2 \\
\hline 4 & 70 & 49.6 & 49.4 & 47.0 & 47.5 & 48.5 & 46.5 \\
\hline 5 & 70 & 54.5 & 52.9 & 51.1 & 51.8 & 51.4 & 48.7 \\
\hline 6.3 & 70 & 57.1 & 57.0 & 54.9 & 55.0 & 63.1 & 62.2 \\
\hline 8 & 70 & 50.8 & 51.0 & 66.3 & 66.7 & 50.9 & 52.6 \\
\hline 10 & 72 & 57.3 & 56.8 & 59.8 & 59.6 & 60.3 & 59.6 \\
\hline 12.5 & 74 & 58.0 & 59.7 & 58.8 & 58.7 & 60.1 & 59.4 \\
\hline 16 & 76 & 58.0 & 56.6 & 76.8 & 76.1 & 76.6 & 75.6 \\
\hline 20 & 78 & 58.1 & 58.1 & 66.5 & 67.6 & 61.1 & 61.3 \\
\hline 25 & 80 & 60.1 & 60.0 & 62.2 & 61.9 & 57.3 & 56.2 \\
\hline 31.5 & 82 & 68.4 & 67.5 & 67.2 & 66.5 & 63.1 & 61.7 \\
\hline 40 & 84 & 63.3 & 64.0 & 64.2 & 64.8 & 66.1 & 63.7 \\
\hline 50 & 86 & 65.5 & 65.1 & 67.9 & 67.7 & 69.9 & 63.6 \\
\hline 63 & 88 & 77.2 & 76.6 & 65.0 & 64.8 & 68.7 & 62.4 \\
\hline 80 & 90 & 65.9 & 64.0 & 68.4 & 68.3 & 66.7 & 65.5 \\
\hline VLz & & 65.5 & 56.2 & 72.8 & 62.5 & 72.0 & 60.6 \\
\hline
\end{tabular}

Table 6 for maximum point $1 / 3$ octave calculation, the floors basement ground vibration is given priority to with $31.5 \mathrm{~Hz}$ and $63 \mathrm{~Hz}$ center frequency, the second floor is $8 \mathrm{~Hz}$ and $16 \mathrm{~Hz}$ center frequency is given priority to, and vertical to the eighth floor with $8 \mathrm{~Hz} \sim 20 \mathrm{~Hz}$ center frequency is given priority to, among them the second and the eighth floor vibration level at the center of the $16 \mathrm{~Hz}$ frequency calculation is beyond specification requirements, and the revised point on the 8th floor on the second floor of the most famous level beyond city regional environmental vibration standard day $70 \mathrm{~dB}$ limit stipulated by the cultural and educational area.

\section{Conclusions}

(1) This article first puts forward the shield through the vibration of the environmentally sensitive area evaluation index and classification standard, and gives its vibration accept criterion, then set up the evaluation system. This article is the work of environmental vibration assessment before a new way of thinking.

(2) Relying on concrete practical engineering, this paper conduct site test and data analysis according to the national standard. Through comparison with test results, verify the application of this system in shield tunnel crossing the effectiveness of environmental sensitive area vibration prediction.

(3) Vibration induced by shield construction environment evaluation system is a kind of quantitative evaluation methods. The system to a certain extent, to predict the influence of the vibration. The establishment of the system through the environmental sensitive area to provide some reference for shield construction.

\section{References}

[1] Guo Fei, Huang Jun, Su Yi, et al. Shield construction process induced vibration source characteristics [J]. Journal of Beijing university of technology, 2014, 40(12): 1820-1827. (in Chinese).

[2] Tao Lian-jin, Guo Fei, Huang Jun, et al. Field tests for environment vibration induced by shield tunneling in sand gravel layer [J]. Journal of Vibration And Shock, 2015, 34(16): 213-218. (in Chinese).

[3] Wang Xin, Han Xuan, Zhou Honglei. Research on environment vibration response induced by metro shield tunneling in central urban area [J]. Civil Engineering Journal, 2015, S2: 309-314. (in Chinese).

[4] Liao Chung-Rong, Wu Shi-Hong, Chen Shue-Cheng. Ground Vibration Induced by Shield Tunneling in Gravel Formation [J]. The 11th strait rain water tunnel and underground engineering and technology seminar 2012, 41-46. (in Chinese).

[5] Nelson, P N, O'Rourke, T D, Flanagan, R F, Kulhawy, F H and Ingraffea, A R. Tunnel boring machine perfor -mance study. Report No. UMTA-06-0100-84-1,448 pp, US Department of Transportation, Washington, DC, 1984.

[6] Richard W. H. Estimation of fault propagation distance from fold shape: Implications for earthquake hazard assessment [J]. Computers and Geotechnics, 2005, 32: 223-244. 
[7] An Junhai, Tao Lianjin, An linxuan, et al. Research on seismic risk assessment system of urban large and complex underground structures $[\mathrm{J}]$. China civil engineering journal, 2015, 48(S2): 118-123.

[8] Zhuang Haiyang, Cheng Shaoge, Chen Guo xing. Numerical simulation and analysis of earthquake damages of Dakai metro station caused by Kobe earthquake [J]. Rock and Soil Mechanics, 2008. 29 (1): 245-250. (in Chinese).

[9] Zheng Xin, Tao Xiaxin, Wang Futong, et al. Mechanism of local amplification in attenuation of ground vibration induced by rail traffic [J]. Journal of Vibration And Shock, 2014, 33 (3): 35-40. (in Chinese).

[10] The People's Republic of China state environmental protection agency. GB10071-88 Urban regional environmental vibration testing method [S] Beijing: China standard publishing house, 1988. (in Chinese).

[11] The People's Republic of China state environmental protection agency. GB10070-88 Urban regional environmental vibration standard [S] Beijing: China standard publishing house, 1988. (in Chinese). 